\title{
Expression profiling of genes modulated by rosmarinic acid (RA) in MCF-7 breast cancer cells
}

\author{
Bogna Juskowiak1, Anna Bogacz', Marlena Wolek1', Adam Kamiński², Izabela Uzar³, \\ Agnieszka Seremak-Mrozikiewicz ${ }^{4}$, Bogusław Czerny ${ }^{1}$, 3 \\ ${ }^{1}$ Department of Stem Cells and Regenerative Medicine, Institute of Natural Fibers and Medicinal Plants, Poznan, Poland \\ ${ }^{2}$ Clinic of Pediatric Orthopedics, Pomeranian Medical University, Szczecin, Poland \\ ${ }^{3}$ Department of Pharmacology and Pharmacoeconomics, Pomeranian Medical University Szczecin, Poland \\ ${ }^{4}$ Division of Perinatology and Women's Diseases, Poznan University of Medical Sciences, Poznan, Poland
}

\begin{abstract}
Objectives: Cancer is the second most common cause of death, with breast cancer (BC) as the most frequently diagnosed neoplasm among females. The origin of $\mathrm{BC}$ is multifactorial and depends on environmental and genetic factors. The disease presents a significant challenge due to its drug resistance and frequent metastasis. Thus, new effective therapies and metastasis prevention are much needed. Rosmarinic acid (RA) is a natural polyphenol which possesses the ability to inhibit $B C$ cell proliferation and demonstrates cytotoxic properties against those cells. In our study, we examined the effect of RA on the expression of ZEB1, MDM2, ABCB1, PTEN and TWIST1 genes in MCF-7 breast cancer cells.

Material and methods: MCF-7 cell cultures were treated with $0.2 \mu$ M doxorubicin (DOX) and 1.5, 15 or $50 \mu$ M of RA. Real-time $P C R$ reaction was performed to analyze gene expression levels.

Results: PCR analysis showed a significant increase of the ZEB1 gene expression, which was about 3-fold for DOX $0.2 \mu \mathrm{M}$, 9-fold for $0.2 \mu \mathrm{M} \mathrm{DOX}+1.5 \mu \mathrm{M} \mathrm{RA}$ and $0.2 \mu \mathrm{M} \mathrm{DOX}+15 \mu \mathrm{M} \mathrm{RA}(\mathrm{p}<0.05)$, and about 6.5 -fold for $0.2 \mu \mathrm{M} \mathrm{DOX}+50 \mu \mathrm{M}$ RA $(p<0.05)$. Furthermore, a decrease of the MDM2 gene expression was observed in all of the examined variants and was about $40-75 \%(p<0.05)$. No influence of DOX and RA combined with DOX on the ABCB1, TWIST1 and PTEN genes was found. Conclusions: The results of our study suggest that RA might be used as an adjuvant therapeutic factor in $B C$ treatment. Key words: breast cancer; rosmarinic acid; molecular study; expression; adjuvant therapy
\end{abstract}

Ginekologia Polska 2018; 89, 10: 541-545

\section{INTRODUCTION}

Breast cancer (BC) is the second most common neoplasm worldwide, and the first among females [1]. It is also the second most common cause of death among women [2]. Over 1.7 million cases of breast cancer are diagnosed annually [3]. Numerous clinical and epidemiological studies have been conducted to better understand the etiology and molecular basis of the disease but the search for effective cancer therapies continues. However, not only strategies of cancer treatment but also ways to prevent the development of the disease are of interest to the researchers. A variety of environmental and lifestyle risk factors affecting the development of breast cancer have already been known and they include the following: ionizing radiation, hormonal therapy, alcohol, diet, obesity and lack or low physical activity [1]. Some dietary ingredients like trans-fatty acids for example may increase the risk of developing chronic diseases, including cardiovascular diseases and cancer [4]. On the other hand, the literature offers many reports about food products, e.g. certain types of fruit, vegetables, grains or herbs, which are negatively correlated with cancer risk, breast cancer being no exception [4-6]. Polyphenols are one of the investigated food compounds which may play an important role in the prevention of BC [7]. They have been reported to take part in the process of interrupting or reversing 
cellular signaling (e.g. NF-KB and AP1 pathways) by affecting intracellular signaling network molecules, which are involved in cell initiation and promotion. Polyphenols are also able to stop or reverse the progression of the disease. Importantly, the effect of their action is probably dose-dependent [8].

Rosmarinic acid (RA) is an ester of caffeic and 3,4-dihydroxyphenyllacitic acid, which commonly occurs in the leaves of Rosmarinus officinalis, from which it can be easily isolated, but it can also be found in other plants of the Lamiaceae and Boraginaceace families $[9,10]$. This natural polyphenol is reported to possess anti-inflammatory, anti-mutagen, anti-bacterial and anti-viral properties. Moreover, RA is an antioxidant, which may help protect tissues from damage caused by reactive oxygen species (ROS) [11]. The results of various studies showed that RA has the ability to inhibit the proliferation of breast cancer cells (MDA-MB-231BO cells), what suggests that this compound can inhibit bone metastasis from breast cancer [10]. The pathway of the NF-кB ligand receptor activator, (RANKL)/RANK/osteoprotegerin and suppression of IL-8 expression are suggested to take part in this process [12]. Moreover, RA shows cytotoxic properties against MCF-7 cells $[13,14]$. Furthermore, the combination of RA and TNF- $a$ is reported to induce apoptosis through inhibition of NF-кB activation in human dermal fibroblasts $[15,16]$. RA also inhibits DNA methyltransferase activity, which is responsible for DNA methylation and silencing of many tumor suppressor genes [13]. However, the number of studies about the influence of RA on BC cells remains limited. The aim of this study was to examine the activity of RA against tumor cells by evaluating the expression level of the following genes: zinc finger E-box binding homeobox 1 (ZEB1), twist homolog 1 (TWIST1), MDM2 p53 binding protein homolog (MDM2), ATP-binding cassette, sub-family $B(A B C B 1)$, phosphatase and tensin homolog (PTEN) involved in cell apoptosis and proliferation.

\section{MATERIAL AND METHODS}

Material

Rosmarinic acid (RA) and doxorubicin (DOX) were provided by Sigma-Aldrich. The MCF-7 cell line containing ER-positive human breast cancer cells was treated in the presence and absence of RA and DOX. MCF-7 cells as control line were cultured without DOX and RA.

\section{Cell culture}

MCF-7 cells were cultured in Dulbecco's modified eagle's medium (DMEM) (Sigma-Andrich). The medium was enriched with $10 \%$ fetal bovine serum (FBS) (Sigma-Aldrich) and $0.1 \%$ penicillin $(100 \mathrm{U} / \mathrm{mL}) /$ streptomycin $(100 \mu \mathrm{g} / \mathrm{mL})$ (Sigma-Aldrich). The cells were cultured in an incubator at $37^{\circ} \mathrm{C}$ with $5 \% \mathrm{CO}_{2}$ atmosphere.

$0.2 \mu \mathrm{M}$ DOX was added to MCF-7/DOX cells. Four types of cell cultures (MCF-7, MCF-7/DOX, MCF-7/RA and MCF-
7/DOX/RA) were seeded at a density of $4 \times 100$ cells $/ \mathrm{mL}$ and cultured for $160 \mathrm{~h}$. After reaching the cell confluence, the medium was removed and the cells were washed with phosphate buffered saline (PBS). Next, the cells were incubated in culture medium without FBS in the presence of RA $(1.5 \mu \mathrm{M}, 15 \mu \mathrm{M}$, $50 \mu \mathrm{M})$, respectively for $24 \mathrm{~h}, 48 \mathrm{~h}, 72 \mathrm{~h}$ and $96 \mathrm{~h}$. Cell growth was analyzed by counting viable cells in the presence of trypan blue (Sigma Aldrich) with a Bucker hemocytometer. To determine the antiproliferative activity for DOX and RA, we carried out the MTT assay adding $10 \mu \mathrm{L}$ of MTT [3-(4, 5-dimethylthiazol-2-yl) -2, 5-diphenyltetrazolium bromide] solution obtained from SIGMA-Aldrich and then incubating for $4 \mathrm{~h}$. The viable cells were visualized by the development of purple color due to formation of formazan crystals which were dissolved with $100 \mu \mathrm{L}$ of isopropyl alcohol at $0.05 \mathrm{~N} \mathrm{HCl}$. Next, the absorbance was measured at $570 \mathrm{~nm}$ on a microplate reader (Infinite 200, TECAN) using the wavelength of $655 \mathrm{~nm}$ as reference.

\section{RNA extraction and CDNA synthesis}

The isolation of total cellular RNA was performed according to the manufacturer's protocol of TriPure Isolation Reagent (Roche). The RNA pellet was washed with 70\% ethanol and dissolved in DEPC water. Next, the analysis of RNA concentration and purity was performed using the absorbance measurement at $260 \mathrm{~nm}$ and $280 \mathrm{~nm}$ in a spectrophotometer (NanoDrop, Thermo Fisher Scientific. The samples were stored in $-80^{\circ} \mathrm{C}$.

$2 \mu \mathrm{g}$ of total RNA were used to synthesize complementary DNA. The reaction was performed using Transcriptor First-Strand Synthesis System (Roche) and oligo(dT)20 primer according to the manufacturer's protocol. The obtained transcripts were used directly for the real-time PCR (RT-PCR) or stored at $-20^{\circ} \mathrm{C}$.

\section{Real-time PCR}

The expression level of the studied genes (ZEB1, $A B C B 1$, MDM2, TWIST1, PTEN) was analyzed by real-time quantitative PCR using RealTime ready Custom Panel 96 kit (Roche). The reaction was conducted using a LightCycler 96 Instrument (Roche, Germany) and a LightCycler 480 Probes Master kit (Roche, Germany). As a housekeeping gene for normalization, the ACTB gene was applied. The activation of PCR reaction was initiated at $95^{\circ} \mathrm{C}$ for $5 \mathrm{~min}$. The denaturation step was carried at $95^{\circ} \mathrm{C}$, an annealing step at a $61^{\circ} \mathrm{C}$ and an extension step at $72^{\circ} \mathrm{C}$. The increase in fluorescence of PCR products was monitored and measured and the data were analyzed with the LightCycler 96 software.

\section{Statistical analysis}

The results were expressed as mean \pm SEM. ANOVA was used to determine the statistical significance of the differences between the control and experimental group. The threshold of significance was $p<0.05$. 


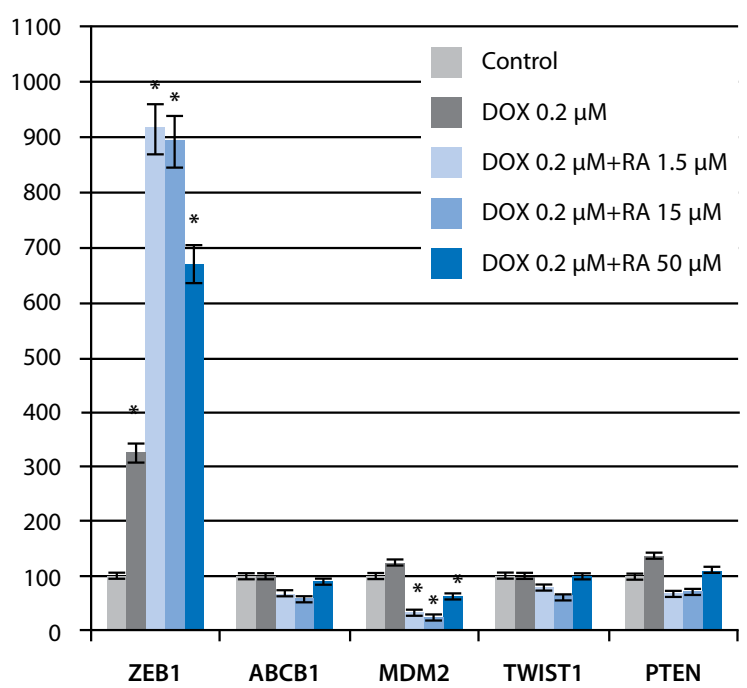

Figure 1. The influence of rosmarinic acid (RA) and doxorubicin (DOX) on gene expression in MCF7 cells after 96h. The control group was defined as $100 \%$. Data were presented as mean \pm SEM. ${ }^{*} p<0.05$ as compared with the control group

\section{MCF-7}

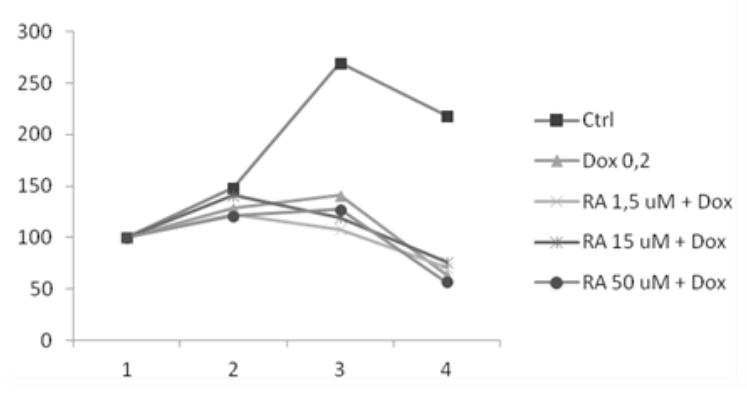

Figure 2. Percentage of MCF7 cell survival after treatment with different concentrations of rosmarinic acid (RA) $(1.5,15$ and $50 \mu \mathrm{M})$, incubated for 4 days in the presence of DOX $(0.2 \mu \mathrm{M})$. Control group without RA and DOX

\section{RESULTS}

In this study, we examined the influence of rosmarinic acid on the expression of selected genes in MCF-7 breast cancer cells, which were treated with $1.5 \mu \mathrm{M}, 15 \mu \mathrm{M}$ and $50 \mu \mathrm{M}$ of RA in $96 \mathrm{~h}$ (Fig. 1). Real-time PCR reaction was performed to define gene expression level. The increased level of the ZEB1 gene expression was observed for MCF-7/DOX and MCF-7/DOX/RA cells (about 3-fold for $0.2 \mu \mathrm{M} \mathrm{DOX,}$ 9-fold for $0.2 \mu \mathrm{M} \mathrm{DOX}+1.5 \mu \mathrm{M}$ and $0.2 \mu \mathrm{M} \mathrm{DOX}+15 \mu \mathrm{M}$ RA and about 6.5-fold for $0.2 \mu \mathrm{M} \mathrm{DOX}+50 \mu \mathrm{M}, \mathrm{p}<0.05$ ). We also noticed a decreased mRNA level of the MDM2 gene in MCF-7 cells when treated with $0.2 \mu \mathrm{M} \mathrm{DOX}+1.5 \mu \mathrm{M} \mathrm{RA}$, $0.2 \mu \mathrm{M} \mathrm{DOX}+15 \mu \mathrm{M}$ RA and $0.2 \mu \mathrm{M} \mathrm{DOX}+50 \mu \mathrm{M}$ RA. No significant influence of RA on the mRNA level was found for the $A B C B 1, T W I S T 1$ and PTEN genes as compared to the control MCF-7 cells.

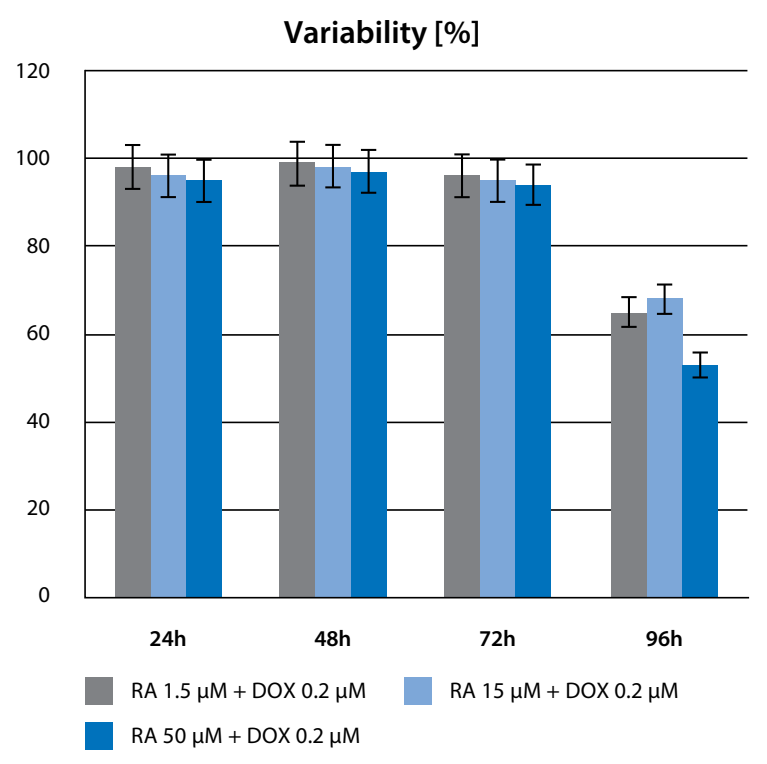

Figure 3. The effect of rosmarinic acid (RA) with doxorubicin (DOX) on the growth of breast cancer cell line. MCF-7 cells were treated with different concentrations of RA for $24,48,72$ and $96 \mathrm{~h}$, and the viability was assessed by MTT assay. Results are expressed as percentage of corresponding control value and represent the mean \pm SD of 3 repeats

Next, we examined the effect of RA on the growth and viability of MCF-7 cells. Using a Bucker hemocytometer, we counted viable cells in the presence of trypan blue. We observed a significant inhibition of cell growth after 4 days of treatment both, for the mixture of DOX with RA and only DOX (Fig. 2). Interestingly, cell growth inhibition was similar, independently of the RA dose.

Moreover, we applied the MTT assay to evaluate the cytotoxic effect of RA. As is shown in Figure 3, treatment of the MCF-7 cells with $1.5 \mu \mathrm{M}, 15 \mu \mathrm{M}$ and $50 \mu \mathrm{M}$ concentrations of RA with combination of $0.2 \mu \mathrm{M}$ DOX resulted in a significant $(p<0.05)$ increase in cell death after 4 days. RA without DOX had no significant effect.

\section{DISCUSSION}

RA shows certain biological and pharmacological activities which can be used for breast cancer prevention and therapy. In this work, the effects RA on the expression level of selected genes (ZEB1, ABCB1, MDM2, TWIST1 and PTEN) in MCF-7 breast cancer cells were analyzed.

In our study, we demonstrated that both, MCF-7/DOX and MCF-7/DOX/RA cells are characterized by significantly increased expression of the ZEB1 gene, with about 2- and 3-fold for breast cancer cells treated with $50 \mu \mathrm{M}$ RA with DOX and 1.5/15 $\mu \mathrm{M}$ RA with DOX, respectively as compared to cells treated only with DOX. This gene is responsible for coding a zinc finger E-box-binding homeobox 1 protein, which binds to specific DNA sequences (E-boxes) and controls the expression of the targeted genes [17]. An aberrant expres- 
sion of ZEB1 has been observed in many cancer types and is considered to be associated with poor prognosis in some cancers (breast, ovarian, lung and pancreatic) [18-21]. The protein encoded by ZEB 1 has been identified as the key factor in $B C$ differentiation and metastasis regulation. Patients with various tumors, including breast cancer, demonstrating high ZEB1 expression responded poorly to chemotherapy [21]. In another study, a positive correlation between human telomerase reverse transcriptase (hTERT) and ZEB1 expression in breast cancer was discovered, which indicates that this gene controls cancer cell proliferation and apoptosis [17]. Therefore, the ZEB1 gene expression is a negative marker in breast cancer treatment, survival and metastasis.

We observed a decrease of the MDM2 gene expression in cells treated with RA in different concentrations. The MDM2 gene encodes a ring finger domain-containing protein MDM2, which belongs to mouse double minute (MDM) family [22]. This protein is a negative regulator of p53 tumor suppressor which binds and ubiquitinates p53, resulting in its easier proteasomal degradation [23]. The increased level of p53 protein is able to induce transcription of MDM2, which leads to degradation of $\mathrm{p} 53$ and generates a negative feedback loop [24]. This process has been observed in various types of cancer, e.g. overexpression of MDM2 occurs in some types of breast cancer [22]. MDM2 has been also reported to negatively affect some other tumor suppressors, like SIRT6 or ERß [22]. Therefore, inhibitors of the MDM2 pathway have attracted much attention of various researchers. A number of small-molecule drugs which inhibit the MDM2 activity have already been discovered [23]. Carnosol, which is a natural phenolic diterpene occurring in rosemary, has been discovered to possess the ability to inhibit MDM2/p53 complex, thus exhibiting anti-cancer properties [25]. In our study, we observed a decreased MDM2 expression in cancer cells treated with RA, which is also a polyphenol present in rosemary, suggesting an anti-cancer effect of RA on breast cancer.

We analyzed the influence of RA on other genes, like $A B C B 1, T W I S T 1$ and PTEN. The $A B C B 1$ gene encodes a P-glycoprotein (P-gp), which is an ATP-dependent efflux pump located in cell membrane. This gene is also associated with multidrug resistance (MDR) and responsible for ATP-dependent efflux of anticancer drugs [26, 27]. Overcoming multidrug resistance to chemotherapeutics is an important aspect of cancer treatment and recovery. The RA also does not influence the TWIST1 gene expression. The transcription factor TWIST, encoded by TWIST1 gene, is an oncoprotein inducing cell migration and invasion in cancer cells, including breast cancer cells, while depletion of TWIST1 inhibits metastasis [28]. Overexpression of TWIST1, often found in various tumors, induces epithelial-mesenchymal transition (EMT), a process involved in cancer metastasis [29]. However, it is an unstable protein and its expression can be upregu- lated, for example by the activation of $\beta$-TRCP ( $\beta$-transducin repeat-containing protein) and/or IKK $\beta$ (Kappa $\beta$ kinase $\beta$ ) [30]. Garcinol, a natural polyphenol, is reported to sensitize breast cancer cells to taxol therapy, which is achieved through the suppression of NF-kB/Twist1 signaling pathway [31]. Our investigation of the possible effect of RA combined with a chemotherapeutic, DOX, on BC cells showed a lack of influence of RA on the TWIST1 expression. Moreover, the PTEN gene expression was examined in breast cancer cells treated with RA. Another phenolic compound, isoliquiritigenin, is reported to have the ability to increase PTEN expression and, as a result, inhibit aberrant Akt signaling [32]. PTEN is a significant negative regulator of the PI3K/Akt/mTOR pathway, which is involved in many cellular actions like proliferation, migration and differentiation. Also, this pathway is involved in cancer cell survival, proliferation and progression [33]. However, RA did not affect the expression level of PTEN in our study.

\section{CONCLUSIONS}

The results of our study may contribute to better understanding of the mechanism of RA effect on cancer. Further studies are necessary to provide evidence for the safety, effectiveness and clinical use of RA in cancer treatment.

\section{ACKNOWLEDGEMENTS}

We wish to express our sincere gratitude to Professor M. Zabel from Poznan University of Medicinal Sciences (Poland) for providing MCF-7 cell line to carry out this work. The study was supported by statutory funds of the Institute of Natural Fibers and Medicinal Plants in Poznan (Poland).

\section{REFERENCES:}

1. Kolak A, Kamińska M, Sygit K, et al. Primary and secondary prevention of breast cancer. Ann Agric Environ Med. 2017; 24(4): 549-553, doi: 10.26444/aaem/75943, indexed in Pubmed: 29284222.

2. Radecka B, Litwiniuk M. Breast cancer in young women. Ginekol Pol. 2016; 87(9): 659-663, doi: 10.5603/GP.2016.0062, indexed in Pubmed: 27723074.

3. Paz MF, de Alencar MV, Gomes Junior AL, et al. Correlations between Risk Factors for Breast Cancer and Genetic Instability in Cancer Patients-A Clinical Perspective Study. Front Genet. 2017; 8: 236, doi: 10.3389/fgene.2017.00236, indexed in Pubmed: 29503660.

4. Liu R. Health-Promoting Components of Fruits and Vegetables in the Diet. Advances in Nutrition. 2013; 4(3), doi: 10.3945/an.112.003517.

5. Turati F, Carioli G, Bravi F, et al. Mediterranean Diet and Breast Cancer Risk. Nutrients. 2018; 10(3), doi: 10.3390/nu10030326, indexed in Pubmed: 29518016.

6. Braakhuis AJ, Campion P, Bishop KS. Reducing Breast Cancer Recurrence: The Role of Dietary Polyphenolics. Nutrients. 2016; 8(9), doi: 10.3390/nu8090547, indexed in Pubmed: 27608040.

7. Valdés A, García-Cañas V, Rocamora-Reverte L, et al. Effect of rosemary polyphenols on human colon cancer cells: transcriptomic profiling and functional enrichment analysis. Genes Nutr. 2013; 8(1): 43-60, doi: 10.1007/s12263-012-0311-9, indexed in Pubmed: 22923011.

8. Ramos S. Cancer chemoprevention and chemotherapy: dietary polyphenols and signalling pathways. Mol Nutr Food Res. 2008; 52(5): 507-526, doi: 10.1002/mnfr.200700326, indexed in Pubmed: 18435439.

9. Sharmila R, Manoharan S. Anti-tumor activity of rosmarinic acid in 7,12-dimethylbenz(a)anthracene (DMBA) induced skin carcinogenesis 
in Swiss albino mice. Indian J Exp Biol. 2012; 50(3): 187-194, indexed in Pubmed: 22439433.

10. Hossan MS, Rahman S, Anwarul Bashar A, et al. Rosmarinic Acid: A Review of Its Anticancer Action. Vol. 2014(3).

11. Karimi N, Rashedi J, Mahdavi Poor B, et al. Cytotoxic effect of rosemary extract on gastric adenocarcinoma (AGS) and esophageal squamous cell carcinoma (KYSE30) cell lines. Gastroenterol Hepatol Bed Bench. 2017; 10(2): 102-107, indexed in Pubmed: 28702133.

12. Xu Y, Jiang $Z$, Ji G, et al. Inhibition of bone metastasis from breast carcinoma by rosmarinic acid. Planta Med. 2010; 76(10): 956-962, doi: 10.1055/s-0029-1240893, indexed in Pubmed: 20157877.

13. Paluszczak J, Krajka-Kuźniak V, Baer-Dubowska W. The effect of dietary polyphenols on the epigenetic regulation of gene expression in MCF7 breast cancer cells. Toxicol Lett. 2010; 192(2): 119-125, doi: 10.1016/j. toxlet.2009.10.010, indexed in Pubmed: 19840838.

14. Berdowska I, Zieliński B, Fecka I, et al. Cytotoxic impact of phenolics from Lamiaceae species on human breast cancer cells. Food Chem. 2013; 141(2): 1313-1321, doi: 10.1016/j.foodchem.2013.03.090, indexed in Pubmed: 23790919.

15. Yesil-Celiktas O, Sevimli C, Bedir E, et al. Inhibitory effects of rosemary extracts, carnosic acid and rosmarinic acid on the growth of various human cancer cell lines. Plant Foods Hum Nutr. 2010; 65(2): 158-163, doi: 10.1007/s11130-010-0166-4, indexed in Pubmed: 20449663.

16. Moon DO, Kim MO, Lee JD, et al. Rosmarinic acid sensitizes cell death through suppression of TNF-alpha-induced NF-kappaB activation and ROS generation in human leukemia U937 cells. Cancer Lett. 2010; 288(2): 183191, doi: 10.1016/j.canlet.2009.06.033, indexed in Pubmed: 19619938.

17. Yu $\mathrm{P}$, Shen $\mathrm{Xi}$, Yang $\mathrm{W}$, et al. ZEB1 stimulates breast cancer growth by up-regulating hTERT expression. Biochem Biophys Res Commun. 2018; 495(4): 2505-2511, doi: 10.1016/j.bbrc.2017.12.139, indexed in Pubmed: 29288666.

18. Karihtala P, Auvinen P, Kauppila S, et al. Vimentin, zeb1 and Sip1 are up-regulated in triple-negative and basal-like breast cancers: association with an aggressive tumour phenotype. Breast Cancer Res Treat. 2013; 138(1): 81-90, doi: 10.1007/s10549-013-2442-0, indexed in Pubmed: 23412770.

19. Bronsert $P$, Kohler I, Timme $S$, et al. Prognostic significance of Zinc finger E-box binding homeobox 1 (ZEB1) expression in cancer cells and cancer-associated fibroblasts in pancreatic head cancer. Surgery. 2014; 156(1): 97-108, doi: 10.1016/j.surg.2014.02.018, indexed in Pubmed: 24929761.

20. Januchowski R, Sterzyńska K, Zaorska K, et al. Analysis of MDR genes expression and cross-resistance in eight drug resistant ovarian cancer cell lines. J Ovarian Res. 2016; 9(1): 65, doi: 10.1186/s13048-016-0278-z, indexed in Pubmed: 27756418.

21. Zhang X, Zhang Z, Zhang Q, et al. ZEB1 confers chemotherapeutic resistance to breast cancer by activating ATM. Cell Death Dis. 2018; 9(2): 57, doi: 10.1038/s41419-017-0087-3, indexed in Pubmed: 29352223.
22. Haupt S, Vijayakumaran R, Miranda PJ, et al. The role of MDM2 and MDM4 in breast cancer development and prevention. J Mol Cell Biol. 2017; 9(1): 53-61, doi: 10.1093/jmcb/mjx007, indexed in Pubmed: 28096293.

23. Zhang Qi, Zeng SX, Lu H. Targeting p53-MDM2-MDMX loop for cancer therapy. Subcell Biochem. 2014; 85: 281-319, doi: 10.1007/978-94-0179211-0_16, indexed in Pubmed: 25201201.

24. Huun J, Gansmo LB, Mannsåker B, et al. The Functional Roles of the MDM2 Splice Variants P2-MDM2-10 and MDM2- $\Delta 5$ in Breast Cancer Cells. Transl Oncol. 2017; 10(5): 806-817, doi: 10.1016/j.tranon.2017.07.006, indexed in Pubmed: 28844019.

25. Giacomelli C, Daniele S, Natali L, et al. Carnosol controls the human glioblastoma stemness features through the epithelial-mesenchymal transition modulation and the induction of cancer stem cell apoptosis. Sci Rep. 2017; 7(1): 15174, doi: 10.1038/s41598-017-15360-2, indexed in Pubmed: 29123181.

26. Tulsyan S, Mittal RD, Mittal B. The effect of $A B C B 1$ polymorphisms on the outcome of breast cancer treatment. Pharmgenomics Pers Med. 2016; 9: 47-58, doi: 10.2147/PGPM.S86672, indexed in Pubmed: 27175090.

27. Liu T, Li Z, Zhang Q, et al. Targeting ABCB1 (MDR1) in multi-drug resistant osteosarcoma cells using the CRISPR-Cas9 system to reverse drug resistance. Oncotarget. 2016; 7(50): 83502-83513, doi: 10.18632/oncotarget.13148, indexed in Pubmed: 27835872.

28. Xu Y, Qin L, Sun T, et al. Twist1 promotes breast cancer invasion and metastasis by silencing Foxa1 expression. Oncogene. 2017; 36(8): 1157-1166, doi: 10.1038/onc.2016.286, indexed in Pubmed: 27524420.

29. Zhu QQ, Ma C, Wang Q, et al. The role of TWIST1 in epithelial-mesenchymal transition and cancers. Tumour Biol. 2016; 37(1): 185-197, doi: 10.1007/s13277-015-4450-7, indexed in Pubmed: 26602382.

30. Zhong J, Ogura K, Wang Z, et al. Degradation of the transcription factor Twist, an oncoprotein that promotes cancer metastasis. Discov Med. 2013; 15(80): 7-15, indexed in Pubmed: 23375009.

31. Tu SH, Chiou YS, Kalyanam N , et al. Garcinol sensitizes breast cancer cells to Taxol through the suppression of caspase-3/iPLA and NF-KB/Twist1 signaling pathways in a mouse $4 \mathrm{~T} 1$ breast tumor model. Food Funct. 2017; 8(3): 1067-1079, doi: 10.1039/c6fo01588c, indexed in Pubmed: 28145547.

32. Peng Fu, Tang H, Liu P, et al. Isoliquiritigenin modulates miR-374a/PTEN/Akt axis to suppress breast cancer tumorigenesis and metastasis. Sci Rep. 2017; 7(1): 9022, doi: 10.1038/s41598-017-08422-y, indexed in Pubmed: 28827662.

33. Moradzadeh M, Hosseini A, Erfanian S, et al. Epigallocatechin-3-gallate promotes apoptosis in human breast cancer T47D cells through down-regulation of PI3K/AKT and Telomerase. Pharmacol Rep. 2017; 69(5): 924-928, doi: 10.1016/j.pharep.2017.04.008, indexed in Pubmed: 28646740. 